\title{
Microwave-Assisted Extraction Studies of Target Analyte Artemisinin from Dried Leaves of Artemisia annua $\mathbf{L}$.
}

\author{
Himanshu Misra, ${ }^{1,2}$ Darshana Mehta, ${ }^{1}$ B. K. Mehta, ${ }^{1}$ and D. C. Jain ${ }^{2}$ \\ ${ }^{1}$ School of Studies in Chemistry and Biochemistry, Vikram University, Ujjain 456 010, Madhya Pradesh, India \\ ${ }^{2}$ Green Technology Department, Ipca Laboratories Limited, Ratlam 457 002, Madhya Pradesh, India \\ Correspondence should be addressed to Himanshu Misra; himanshumisra1@rediffmail.com and D. C. Jain; dc_52@rediffmail.com
} Received 31 October 2012; Revised 28 January 2013; Accepted 11 February 2013

Academic Editor: Cyril Parkanyi

Copyright (C) 2013 Himanshu Misra et al. This is an open access article distributed under the Creative Commons Attribution License, which permits unrestricted use, distribution, and reproduction in any medium, provided the original work is properly cited.

\begin{abstract}
Artemisia annua L. (Asteraceae) is an annual herb native of Asia. This plant has been used for many centuries in traditional Chinese medicine for the treatment of fever and malaria. Conventional methods for the extraction of artemisinin from A. annua including solvent extraction, Soxhlet extraction, and heat reflux extraction are characterized by long extraction times and the consumption of large volume of solvents. A simple, rapid, and precise microwave-assisted extraction process was optimized for fast sample preparation for the faster quantitative determination of artemisinin, potential new generation antimalarial drug, from dried leaves of Artemisia anпиа L. A simple experiment was designed for the optimization of the appropriate solvent under same extraction conditions. The selected appropriate solvent was then standardized for various different extraction variables. The major parameters studied showed effects on extraction efficiency including processing time, strength of microwave, moisture content, volume and nature of the solvent. The most favorable conditions were obtained by using plant material of 25 mesh (particle size) extracted with acetone for 120 seconds at $160 \mathrm{~W}$ (i.e., $20 \%$ of total power). Quantitative analysis was performed using thin-layer chromatography coupled with a densitometer (TLC densitometry). The results showed that MAE can be used as an efficient and rapid method for the extraction of the active components from plants.
\end{abstract}

\section{Introduction}

Artemisia annua L. (Asteraceae, formerly Compositae), also known as qinghao, annual or sweet wormwood, is an annual herb native of Asia. This plant has been used for many centuries in traditional Chinese medicine for the treatment of fever and malaria. 300 million illnesses and at least one million deaths are caused by malaria in a year. Malaria is often referred to as disease of the poor. Therefore, it is the need of the hour to develop an effective and low-cost drug to cure malaria. Artemisinin (Figure 1), a sesquiterpene lactone with an endoperoxide bridge, which is rare in secondary metabolites, is isolated from Artemisia annua L. Artemisinin is responsible for the therapeutic effects of the plant. It acts as a bullet to kill the Plasmodium, causative agent of malaria by oxidative damage. Newer research shows serious anticancer [1] benefits too, as a bonus of the plant.

Synthetic routes [2-4] of artemisinin are very tedious and expensive compared to its natural isolation, and thus, synthetic artemisinin is not a commercially viable option. Low and variable concentration of artemisinin $(0.01 \%-$ $1.40 \%)$ in plant is a serious limitation for commercialization of the drug. Hence, a low-cost and effective extraction process is highly desirable. Conventional methods like percolation/solid-liquid extractions with toluene, $n$-hexane, or petroleum ether are currently the most applied techniques [5], with extraction time that can vary from a few hours to several hours or even days. Microwave-assisted extraction (MAE) technique has emerged as an interesting alternative to conventional liquid solvent extraction methods, especially in case of herbals or biological samples.

Microwave-assisted extraction (MAE) has received increasing attention as a potential alternative to solid-liquid extractions (SLE) for the extraction of secondary metabolites from plants. After the first report on the use of microwave heating for organic extraction [6], numerous laboratories have investigated the analytical possibilities of this new extraction technique $[7,8]$. MAE depends on the dielectric 


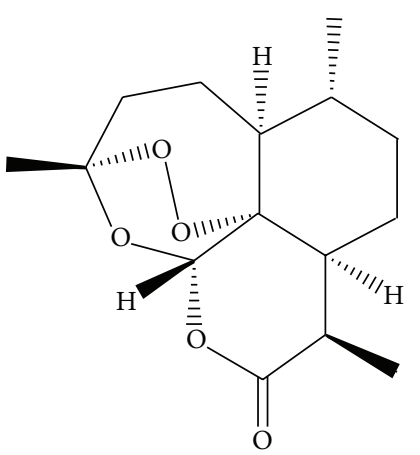

FIgURE 1: Artemisinin.

susceptibility of both solvent and matrices. Disruption of hydrogen bonds, resulting from the dipole rotation of the molecules, and migration of dissolved ions facilitate the penetration of solvent molecules into the matrix and allow the solvation of components to be extracted [9]. MAE seems particularly promising for the extraction of compounds with medium to high polarity from solid matrix.

The present work describes the development of a fast, cost-effective, and enhanced extraction procedure of target analyte artemisinin from dried leaves of Artemisia annua L. by microwaves for fast analytical-scale sample preparation. Much attention has been paid to develop faster extraction techniques, but previous works $[10,11]$ in this direction are not so efficient. The major parameters studied are the effect on extraction efficiency including mesh size of biological sample, processing time, strength of microwaves, moisture content, volume and nature of solvent compared with normal solid-liquid (soxhlet) extraction process. The process shows the advantage of shorter extraction time with increased content and low solvent consumption. Thin-layer chromatography (TLC) is a powerful tool for separating mixtures of compounds of widely different polarity and can provide a chromatographic "fingerprint" of a plant extract, very useful for identification purposes, and usually a photograph can be attached to the analysis certificate $[12,13]$. Here, quantitative analysis of artemisinin was performed using previously reported TLC-DM (thin-layer chromatography coupled with densitometry) method [14] with some modifications in sample preparation technique to avoid errors, and densitometric evaluation of sample and standard tracks was performed at a single wavelength $(540 \mathrm{~nm})$.

\section{Experimental}

2.1. Plant Material. Artemisia annua L. were grown in an experimental field at Ipca Laboratories Ltd., Ratlam (M.P.), India, after transfer of agroechnology of high yielding $A$. annua variety "Jeevan Raksha” developed at CIMAP, Lucknow. The fresh leaves were dried in shade, finely crushed, sieved, and stored. Content of artemisinin in this raw plant material was determined to be $0.60 \%$ as analyzed by TLC densitometric method using soxhlet extraction.
2.2. Chemicals and Reagents. All solvents used in this study were of analytical grade. Precoated silica gel $60 \mathrm{~F}_{254}$ TLC plates were purchased from Merck (Darmstadt, Germany). Artemisinin was isolated from A. annua L., and its identity was confirmed by its spectral analysis [15].

Anisaldehyde-sulphuric acid reagent was prepared by mixing $5 \mathrm{~mL}$ of anisaldehyde in $500 \mathrm{~mL}$ glacial acetic acid kept in a beaker and stirred well for 5 minutes. Now, $10 \mathrm{~mL}$ of concentrated $\mathrm{H}_{2} \mathrm{SO}_{4}(98 \%)$ was added slowly to the aforementioned solution through side wall of the beaker with gentle stirring [16].

2.3. Apparatus. A digitally controlled domestic microwave oven with operating power 160-800 Watt was used for MAE. Minimal operation time and power were 10 seconds at $160 \mathrm{~W}$ (20\% power).

A computerized TLC scanner 3 with winCATS online Planar Chromatography Manager version 1.3.4 (CAMAG, Switzerland) was used for quantitative chromatographic evaluation of test spots. Camag's Linomat 5 was utilized for nitrogen gas-assisted and controlled application of sample spots on to TLC plate.

2.4. Standard Solution Preparation. $50 \mathrm{mg}$ of pure artemisinin was taken into a $50 \mathrm{~mL}$ volumetric flask, dissolved in methanol, made up to $50 \mathrm{~mL}$, sonicated for 10 minutes, and left for an hour. A portion $(10 \mathrm{~mL})$ of this solution was diluted up to $50 \mathrm{~mL}$ with methanol, sonicated for 10 minutes, and left for an hour. This standard solution of artemisinin was used in TLC densitometric analysis against test samples.

2.5. Linearity Range. A ten-point-scale calibration curve was prepared using the standard artemisinin solution. Linearity was obtained between 0.10 and $1.0 \mathrm{mg} \mathrm{mL}^{-1}$ (applied volume was $2 \mu \mathrm{L} ; 200 \mathrm{ng}$ to $2000 \mathrm{ng}$ per zone) with a correlation coefficient of 0.9927 (via height) and 0.9952 (via area), respectively. Linear regression equations were as follows:

$$
\begin{aligned}
& \text { Regression via height: Linear } \\
& \begin{array}{r}
Y=m . X+C=0.138 X+22.581 \\
r=0.9927 \mathrm{sdv}=5.46,
\end{array}
\end{aligned}
$$

Regression via area: Linear

$$
\begin{array}{r}
Y=m \cdot X+C=7.673 X+737.232 \\
r=0.9952 \mathrm{sdv}=4.87,
\end{array}
$$

where $m$ is the slope, $X$ is the analyte concentration, and $C$ is the intercept. It concludes that the single standard solution can be used for the available range of target analyte.

2.6. Peak Purity. Complete UV-spectral (190-790 nm) comparison of eluted test artemisinin spot on to TLC plate was matched using Camag's software. A correlation limit $(r)$ for a test artemisinin spot start to spot middle and spot middle to spot end was 0.9983 and 0.9962 , respectively, as shown in the overlay UV absorption spectra of a resolved artemisinin spot 
TABLE 1: Solvent selection-effect of nature of solvent on the recovery of artemisinin from leaves of Artemisia annua L.

\begin{tabular}{lccc}
\hline Extraction method & Solvents & Dielectric constant & \% Artemisinin recovered (\% dry weight $)^{\mathrm{b}}( \pm \mathrm{SD})$ \\
\hline \multirow{2}{*}{ Soxhlet } & $n$-hexane & 1.89 & $0.60( \pm 0.01)$ \\
& Petroleum ether $\left(60-80^{\circ} \mathrm{C}\right)$ & $2.00-2.20$ & $0.62( \pm 0.02)$ \\
\hline & Cyclohexane & 2.02 & $0.18( \pm 0.01)$ \\
& $n$-hexane & 1.89 & $0.31( \pm 0.01)$ \\
& Petroleum ether $\left(60-80^{\circ} \mathrm{C}\right)$ & $2.00-2.20$ & $0.30( \pm 0.01)$ \\
$\mathrm{MAE}^{\mathrm{a}}$ & Ethyl acetate & 6.02 & $0.63( \pm 0.02)$ \\
& Chloroform & 4.81 & $0.60( \pm 0.02)$ \\
& Acetone & 20.7 & $0.63( \pm 0.01)$ \\
& Methanol & 32.63 & $0.46( \pm 0.02)$ \\
\end{tabular}

${ }^{\mathrm{a}} \mathrm{MAE}$ conditions (14 mesh, $100 \mathrm{mg}, 5 \mathrm{~mL}, 160 \mathrm{~W}$, and $60 \mathrm{~s}$ ).

${ }^{\mathrm{b}}$ Two cycles of extractions carried out in each case.

TABLE 2: Influence of mesh, solvent volume, time, and power of microwave irradiation on recovery of artemisinin.

\begin{tabular}{|c|c|c|c|c|c|c|}
\hline Solvent & Material to solvent ratio & $\begin{array}{l}\text { Particle size } \\
\text { (Mesh) }\end{array}$ & $\begin{array}{l}\text { Irradiation time/cycle } \\
\text { (Second) }\end{array}$ & $\begin{array}{c}\text { Irradiation } \\
\text { power (Watt) }\end{array}$ & $\begin{array}{c}\% \text { Mean artemisinin } \\
\text { recovered }( \pm \mathrm{SD}) \\
(\% \text { dry weight })^{\mathrm{b}} n=3\end{array}$ & $\%$ RSD \\
\hline Acetone $^{\mathrm{a}}$ & $100 \mathrm{mg}: 5 \mathrm{~mL}$ & 14 & 60 & 160 & $0.63( \pm 0.01)$ & 1.59 \\
\hline \multirow{3}{*}{ Acetone } & \multirow{3}{*}{$100 \mathrm{mg}: 5 \mathrm{~mL}$} & \multirow{3}{*}{25} & 60 & 160 & $0.64( \pm 0.02)$ & 2.40 \\
\hline & & & 60 & 320 & $0.64( \pm 0.02)$ & 3.13 \\
\hline & & & 120 & 160 & $0.69( \pm 0.01)$ & 0.84 \\
\hline \multirow{3}{*}{ Acetone } & \multirow{3}{*}{$100 \mathrm{mg}: 10 \mathrm{~mL}$} & \multirow{3}{*}{25} & 60 & 160 & $0.71( \pm 0.01)$ & 1.63 \\
\hline & & & 60 & 320 & $0.69( \pm 0.02)$ & 2.90 \\
\hline & & & 120 & 160 & $0.73( \pm 0.01)$ & 1.37 \\
\hline
\end{tabular}

${ }^{a}$ Taken from Table 1 as a control value to analyze the effect of mesh size on artemisinin recovery.

${ }^{\mathrm{b}}$ Two cycles of extraction were carried out in each case.

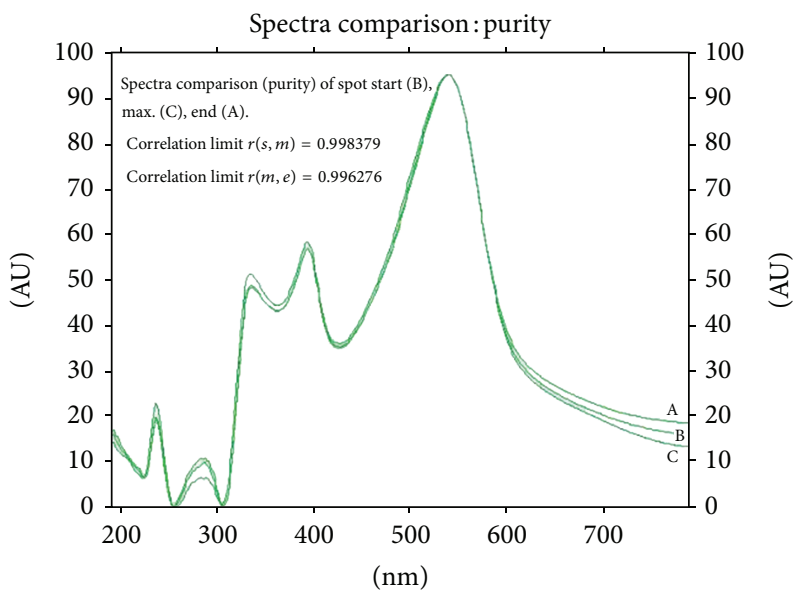

FIGURE 2: Overlay UV absorption spectra of resolved artemisinin spot after postchromatographic derivatization with anisaldehydesulphuric acid reagent showing purity of up $[r(s, m)]$ and down slopes $[r(m, e)]$.

after postchromatographic derivatization with anisaldehydesulfuric acid reagent showing purity of up and down slopes (Figure 2).
2.7. Soxhlet Extraction and Test Sample Preparation. A sample of plant material (1 $\mathrm{g}, 14$ mesh) was placed into an extraction thimble; soxhlet extraction was performed for $5 \mathrm{~h}$ with $170 \mathrm{~mL} n$-hexane. The solvent was then evaporated in vacuo to dryness via rotavapor (Buchi, Switzerland) and redissolved in $50 \mathrm{~mL}$ methanol for quantitative analysis by TLC densitometry.

2.8. Microwave-Assisted Extraction (MAE) and Test Sample Preparation. $100 \mathrm{mg}$ of dried plant material (14 and $25 \mathrm{mesh}$ ) was taken into a $30 \mathrm{~mL}$ glass vial with solvent ( $n$-hexane to acetonitrile; $5-10 \mathrm{~mL}$ ) and placed into the extraction cabinet. Power (160-320 W) was applied for different time periods (10 s to $3 \mathrm{~min}$ ) as shown in Tables 1,2 , and 3. After irradiation was complete, each sample was filtered in a test tube. $5 \mathrm{~mL}$ of solvent was then added again to the sample vial for the second cycle of extraction. Each test sample was washed with $2 \mathrm{~mL}$ of corresponding solvent at the end of the second cycle of extraction. Total volume of test sample was evaporated in vacuo to dryness via rotavapor (Buchi, Switzerland) and redissolved in $5 \mathrm{~mL}$ methanol for quantitative analysis by TLC densitometry. 
TABLE 3: Effect of the volume of water soaking on artemisinin recovery ${ }^{\mathrm{a}}$.

\begin{tabular}{lcccc}
\hline Solvent & Volume of water applied & Impregnation time (Second) & \% Mean artemisinin recovery $( \pm$ SD) & $\%$ RSD \\
\hline \multirow{3}{*}{ Acetonitrile } & $\mathrm{ND}^{\mathrm{a}}$ & $\mathrm{ND}^{\mathrm{a}}$ & $0.67( \pm 0.02)$ & 2.29 \\
& $100 \mu \mathrm{L}^{\mathrm{b}}$ & 180 & $0.68( \pm 0.01)$ & 0.85 \\
& $200 \mu \mathrm{L}^{\mathrm{b}}$ & & $0.72( \pm 0.01)$ & 1.39 \\
\hline
\end{tabular}

${ }^{a}$ Not done (one sample extracted as per the conditions: $25 \mathrm{mesh}, 100 \mathrm{mg}, 5 \mathrm{~mL}, 160 \mathrm{~W}$, and $60 \mathrm{~s}$ but without water application and impregnation).

${ }^{\mathrm{b}}$ MAE conditions ( $25 \mathrm{mesh}, 100 \mathrm{mg}, 10 \mathrm{~mL}, 160 \mathrm{~W}$, and $180 \mathrm{~s}$ ).

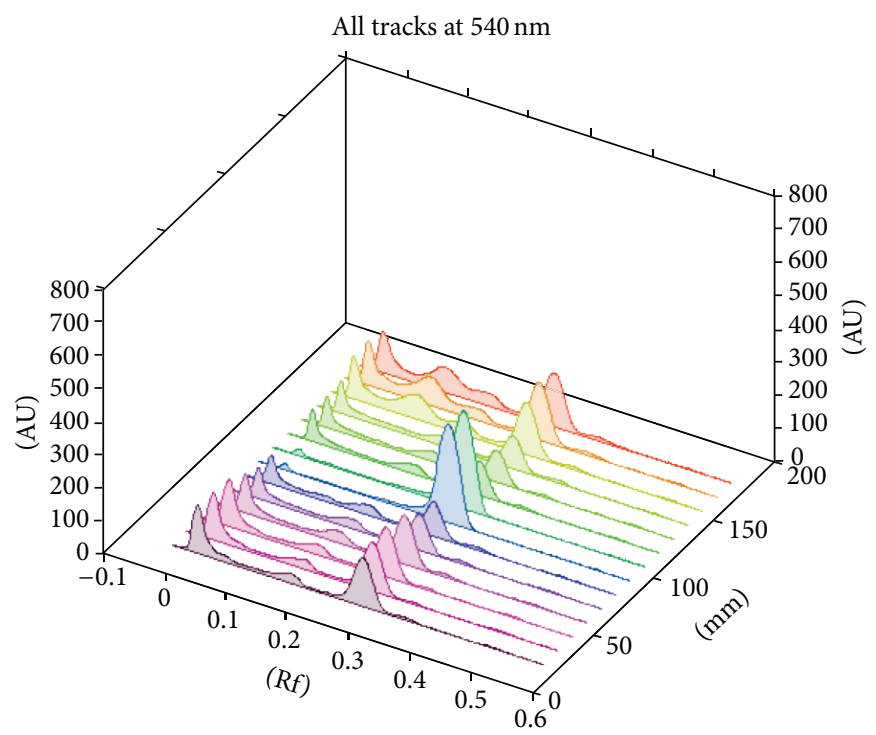

FIGURE 3: 3D spectrographic image showing chromatographic separation of artemisinin over TLC.

2.9. TLC-Densitometric Analysis. In chromatographic analysis, $10 \mu \mathrm{L}$ of the standard artemisinin solution was spotted against $10 \mu \mathrm{L}$ of test samples on precoated silica gel TLC plates $(20 \times 20 \mathrm{~cm}) 60 \mathrm{~F}_{254}$ (Merck, Germany) with a layer thickness of $0.25 \mathrm{~mm}$. Chromatography was carried out in a Camag twin-trough chamber with $n$-hexane : diethyl ether $(1: 1, \mathrm{v} / \mathrm{v})$ and the plates were developed up to $70 \%$ of plate height. Plates were taken off and dried, and spots were visualized by immersing the plates in a freshly prepared mixture of glacial acetic acid: concentrated $\mathrm{H}_{2} \mathrm{SO}_{4}$ : anisaldehyde (50:1:0.5, $\mathrm{v} / \mathrm{v} / \mathrm{v}$ ), followed by heating of the plates at $110^{\circ} \mathrm{C}$ for 15 minutes to visualize a pink-colored spot of artemisinin. For quantification, TLC spot corresponding to artemisinin was scanned using camag's TLC scanner-3 at $540 \mathrm{~nm}$ wavelength using a slit dimension of $6.00 \times 0.45 \mathrm{~mm}$, with a scanning speed of $20 \mathrm{~mm} / \mathrm{s}$ and data resolution of $100 \mu \mathrm{m} / \mathrm{step}$. Chromatographic separation of artemisinin over TLC is shown by a 3D spectrographic image (Figure 3).

\section{Results and Discussion}

3.1. Soxhlet Extraction. Since liquid solvent extraction with $n$-hexane and petroleum ether is the most currently applied technique used for extraction of artemisinin from dry aerial parts of $A$. annua L., therefore, these two solvents were used for extraction of artemisinin by soxhlet $(5 \mathrm{~h})$. This procedure allowed the recovery of artemisinin $0.60 \%$ and $0.62 \%$ (by dry weight) with $n$-hexane and petroleum ether $\left(60-80^{\circ} \mathrm{C}\right)$, respectively. These values will be considered as reference values in the following discussion.

3.2. Microwave-Assisted Extraction. The effects on the efficiency of extraction resulting from alteration of various parameters, including the nature and volume of the extracting solvent, sample moisture, extraction time, power of irradiation, and particle size, were studied. Microwave conditions for the initial experiment for the selection of solvent were $100 \mathrm{mg}, 5 \mathrm{~mL}, 160 \mathrm{~W}$, and $60 \mathrm{~s}$. Each sample was extracted twice.

3.3. Nature of Extracting Solvent. Solvents of different polarity ranging from $n$-hexane to acetonitrile were tested (Table 1). The operating power of the apparatus was set at $160 \mathrm{~W}$ (20\% of maximal value). MAE extraction with cyclohexane, petroleum ether $\left(60-80^{\circ} \mathrm{C}\right), n$-hexane, and methanol yielded poor recovery of artemisinin at the same parameters in comparison to soxhlet extraction since methanol bumps frequently within $6 \mathrm{~s}$ of microwave irradiation $(160 \mathrm{~W}$, minimal possible power), which leads to uneven recoveries of artemisinin. Chloroform, which has a lower dielectric constant than methanol, gave good recovery. $n$-hexane, cyclohexane, and petroleum ether did not seem to be suitable for extraction at the same parameters. Though having much difference in their dielectric constant, ethyl acetate and acetone 
gave similar recoveries. Similar was the case with chloroform and acetonitrile. In this way, acetone and acetonitrile were selected (higher dielectric constants with greater difference) for further experiments.

3.4. Volume of Extracting Solvent. When the volume of acetone, used for the extraction, was varied from $5 \mathrm{~mL}$ to $10 \mathrm{~mL}$, a slight but considerable influence on the recovery was observed confirming that solvent volume was also a key factor of investigation (Table 2). Best results were obtained when the material-to-solvent ratio was $100 \mathrm{mg}: 10 \mathrm{~mL}$.

3.5. Particle Size. It has been reported that recoveries of withanolides increased with finer samples [17]; therefore, in order to study the effect of particle size, two different particle sizes 14 mesh (coarse fraction) and 25 mesh (fine fraction) were selected in the present study. $100 \mathrm{mg}$ of each fraction was submitted to MAE ( $5 \mathrm{~mL}$, acetone, $160 \mathrm{~W}$, and $60 \mathrm{~s}$ ). No significant difference in recoveries was observed (Table 2).

3.6. Strength and Duration of Microwave Irradiation. It can be deduced from Table 2 that microwave irradiation for more duration with lesser microwave strength yielded better recoveries of artemisinin than that in lesser time with higher strength. It may be due to the reason that in open vessel microwave extraction, when higher microwave strength was applied, solvent gets evaporated rapidly. Since solvent is the surrounding media for extraction of artemisinin, it gave poor recoveries. But when lesser microwave strength is applied for more time, there is sufficient time for solvent to dissolve target analyte within it, resulting in enhanced recoveries of target analyte (artemisinin). So, more irradiation time with lesser strength $(100 \mathrm{mg}, 10 \mathrm{~mL}$, acetone, $160 \mathrm{w}$, and $120 \mathrm{~s}$ ) was preferred.

3.7. Sample Moisture (Water Soaking). It has been reported that impregnation of matrix with water facilitates extraction giving better recoveries $[17,18]$. Therefore, the influence of moisture (impregnation time kept constant) on the recovery of artemisinin was studied. Water $(100 \mu \mathrm{L}$ to $200 \mu \mathrm{L})$ was added immediately for $30 \mathrm{~min}$ prior to acetonitrile (water and acetonitrile both are solvents having high dielectric constants) extraction (10 mL, $160 \mathrm{~W}$, and $3 \mathrm{~min})$. As shown in Table 3, recovery was slightly improved, when $200 \mu \mathrm{L}$ of water was added compared to $100 \mu \mathrm{L}$. It was probably due to complete sample moistening, leading to a more homogeneous irradiation.

Solvents of different polarity were tested in the first set of experiment (Table 1) for the selection of appropriate solvent. Selection of solvents was based on some characteristic factors; for example, the solvent should be easily evaporable, and density should be less than that of plant material so that extracting solvent should penetrate the plant material completely yielding greater recoveries of target analyte artemisinin. So, selection of acetone and acetonitrile (both have high value of dielectric constant with remarkable difference) instead of ethyl acetate and chloroform was based on keeping the aforementioned factors in mind. Extraction with chloroform caused problem during filtration since the whole material comes out of the extraction vial due to the higher density of chloroform compared to plant material.

While studying the effect of irradiation power and duration in the second set of experiment (Table 2), an increase in the power of irradiation had no effect on artemisinin recovery, whereas an increase in duration of irradiation showed increased recovery of artemisinin. The diluted samples showed remarkably better recoveries.

In the third set of experiment (Table 3), the effect of higher dielectric constant solvent (Acetonitrile) and the effect of water soaking on extraction efficiency were studied. Samples that were given greater water soaking $(200 \mu \mathrm{L})$ prior to extraction for $30 \mathrm{~min}$ showed better recovery of artemisinin.

In microwave-assisted extraction, the polarity of solvent plays a very important role in the extraction of natural products as polar solvents with higher dielectric constant can absorb more microwave energy. Microwave-transparent and microwave-nontransparent/absorbed nature of solvents and matrices was described [19], on which the quality of extraction and the yield of target analyte depends. Plant material absorbs microwave energy without much hindrance when extracted with microwave-transparent solvent, because the solvent does not absorb energy; only plant material absorbs it. At the same time, cellular structures of plants like glands/trichomes contain much water. This water absorbs microwave energy quickly creating a sudden increase in temperature inside the cells, which rupture cell wall and release chemical components into the surrounding medium, that is, solvent. As in our study, Table 3 shows increased recovery of artemisinin when $200 \mu \mathrm{L}$ of water was added and allowed to impregnate for half an hour instead of recovery from $100 \mu \mathrm{L}$. Using microwave irradiation, the degradative effects of higher temperatures can be avoided [6]. The energy of the microwave facilitates rapid disruption from the matrix.

\section{Conclusion}

The optimized microwave-assisted extraction method gave recoveries that were in good agreement with those obtained from the soxhlet extraction using $n$-hexane and petroleum ether $\left(60-80^{\circ}\right)$ as solvents. The optimized MAE conditions using acetone were $100 \mathrm{mg}, 10 \mathrm{~mL}, 160$ watt, 120 seconds, and 2 cycles of extraction. Yield of target analyte artemisinin, recovered by this method, was $21.67 \%$ higher than that of soxhlet extraction using $n$-hexane. Use of MAE in the extraction and preparation of samples for testing is a green process due to the lowest solvent drainage and high-energy saving, thus very economical. This study not only focuses on the rapid and cost-effective sample preparation for sample under test but also gives a hint for large-scale extraction of artemisinin.

\section{Disclaimer}

The authors have used domestic microwave oven, because of financial problems, which are not safe for chemical processing. The readers of this research paper are strictly advised 
that domestic microwave must not be used for any type of chemical processing. The authors would not be responsible for any loss occurred by the use of the method described or equipment(s) used in this study.

\section{Conflict of Interests}

The authors declare that they have no conflict of interests (this paper is part of Ph.D. of one of the authors, Himanshu Misra, and is not intended for any financial gains).

\section{Acknowledgment}

The authors are very grateful to IPCA Laboratories Limited, Ratlam, India, for providing authentic plant material, permission for research facility, and instrumental analysis with a keen interest in the work.

\section{References}

[1] M. M. Al-Oqail, A. M. Galal, M. S. Ahmad, A. M. Al-Fishawi, and F. S. El-Feraly, "New bioactive azaartemisinin derivatives," Molecules, vol. 8, no. 12, pp. 901-909, 2003.

[2] M. A. Avery, C. Jennings-White, and W. K. M. Chong, "The total synthesis of (+)-artemesinin and (+)-9-desmethylartemesinin," Tetrahedron Letters, vol. 28, no. 40, pp. 4629-4632, 1987.

[3] T. Ravindranathan, M. A. Kumar, R. B. Menon, and S. V. Hiremath, "Stereoselective synthesis of artemisinin," Tetrahedron Letters, vol. 31, no. 5, pp. 755-758, 1990.

[4] J. S. Yadav, R. Satheesh Babu, and G. Sabitha, "Total synthesis of (+) artemisinin," ARKIVOC, vol. 2003, no. 3, pp. 125-139, 2003.

[5] H. N. ElSohly, E. M. Croom, and M. A. ElSohly, "Analysis of the antimalarial sesquiterpene artemisinin in Artemisia annua by high-performance liquid chromatography (HPLC) with postcolumn derivatization and ultraviolet detection," Pharmaceutical Research, vol. 4, no. 3, pp. 258-260, 1987.

[6] K. Ganzler, A. Salgó, and K. Valkó, "Microwave extraction. A novel sample preparation method for chromatography," Journal of Chromatography A, vol. 371, pp. 299-306, 1986.

[7] A. Sinquin, T. Gorner, and E. Dellacherie, "Use of microwaves in analytical chemistry," Analusis, vol. 21, no. 1, pp. 1-10, 1993.

[8] M. Waksmundzka-Hajnos, A. Petruczynik, A. Dragan, D. Wianowska, and A. L. Dawidowicz, "Effect of extraction method on the yield of furanocoumarins from fruits of Archangelica officinalis Hoffm," Phytochemical Analysis, vol. 15, no. 5, pp. 313319, 2004.

[9] K. Ganzler, I. Szinai, and A. Salgo, "Effective sample preparation method for extracting biologically active compounds from different matrices by a microwave technique," Journal of Chromatography, vol. 520, pp. 257-262, 1990.

[10] P. Christen and J. L. Veuthey, "New trends in extraction, identification and quantification of artemisinin and its derivatives," Current Medicinal Chemistry, vol. 8, no. 15, pp. 1827-1839, 2001.

[11] J. Y. Hao, W. Han, S. D. Huang, B. Y. Xue, and X. Deng, "Microwave-assisted extraction of artemisinin from Artemisia annua L," Separation and Purification Technology, vol. 28, no. 3, pp. 191196, 2002.

[12] A. Srivastava, H. Misra, R. K. Verma, and M. M. Gupta, "Chemical fingerprinting of Andrographis paniculata using HPLC,
HPTLC and densitometry," Phytochemical Analysis, vol. 15, no. 5, pp. 280-285, 2004.

[13] M. M. Gupta, A. Srivastava, A. K. Tripathi, H. Misra, and R. K. Verma, "Use of HPTLC, HPLC, and densitometry for qualitative separation of indole alkaloids from Rauvolfia serpentina roots," Journal of Planar Chromatography-Modern TLC, vol. 19, no. 110, pp. 282-287, 2006.

[14] M. M. Gupta, D. C. Jain, R. K. Verma, and A. P. Gupta, "A rapid analytical method for estimation of artemisinin in Artemisia annua," Journal of Medicinal and Aromatic Plant Sciences, vol. 18, no. 1, pp. 5-6, 1996.

[15] P. Bhandari, A. P. Gupta, B. Singh, and V. K. Kaul, "Simultaneous densitometric determination of artemisinin, artemisinic acid and arteannuin-B in Artemisia annua using reversed-phase thin layer chromatography," Journal of Separation Science, vol. 28, no. 17, pp. 2288-2292, 2005.

[16] H. Misra, B. K. Dwivedi, D. Mehta, B. K. Mehta, and D. C. Jain, "Development and validation of high performance thin-layer chromatographic method for determination of $\alpha$-mangostin in fruit pericarp of mangosteen plant (Garcinia mangostana L.) using ultraviolet-visible detection," Records of Natural Products, vol. 3, no. 4, pp. 178-186, 2009.

[17] B. Kaufmann, P. Christen, and J. L. Veuthey, "Parameters affecting microwave-assisted extraction of withanolides," Phytochemical Analysis, vol. 12, no. 5, pp. 327-331, 2001.

[18] J. R. J. Pare, M. Sigomin, and J. Lapointe, "Microwave extraction of volatile oils and apparatus therefor," European patent no. 0485668 A1, 1992.

[19] J. R. J. Pare, M. Sigomin, and J. Lapointe, "Microwave-assisted natural products extraction," United States patent no. 5,002,784, 1991. 

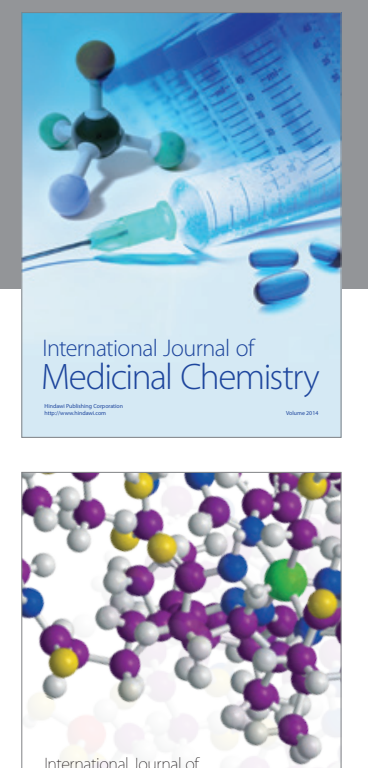

\section{Carbohydrate} Chemistry

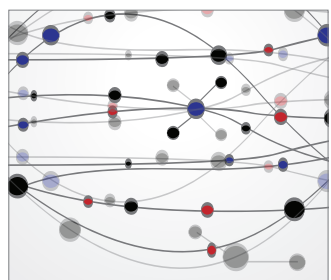

The Scientific World Journal
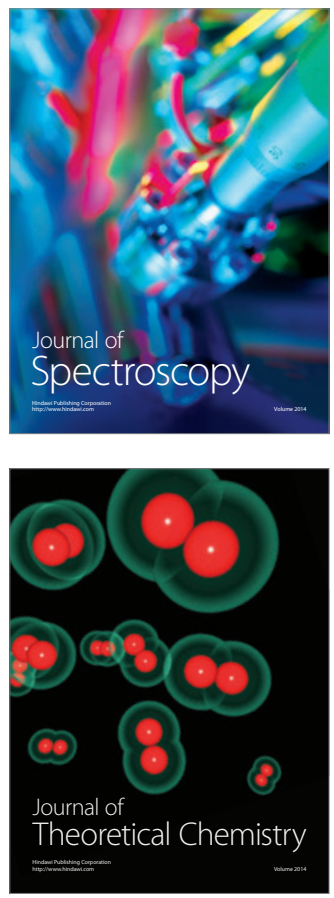
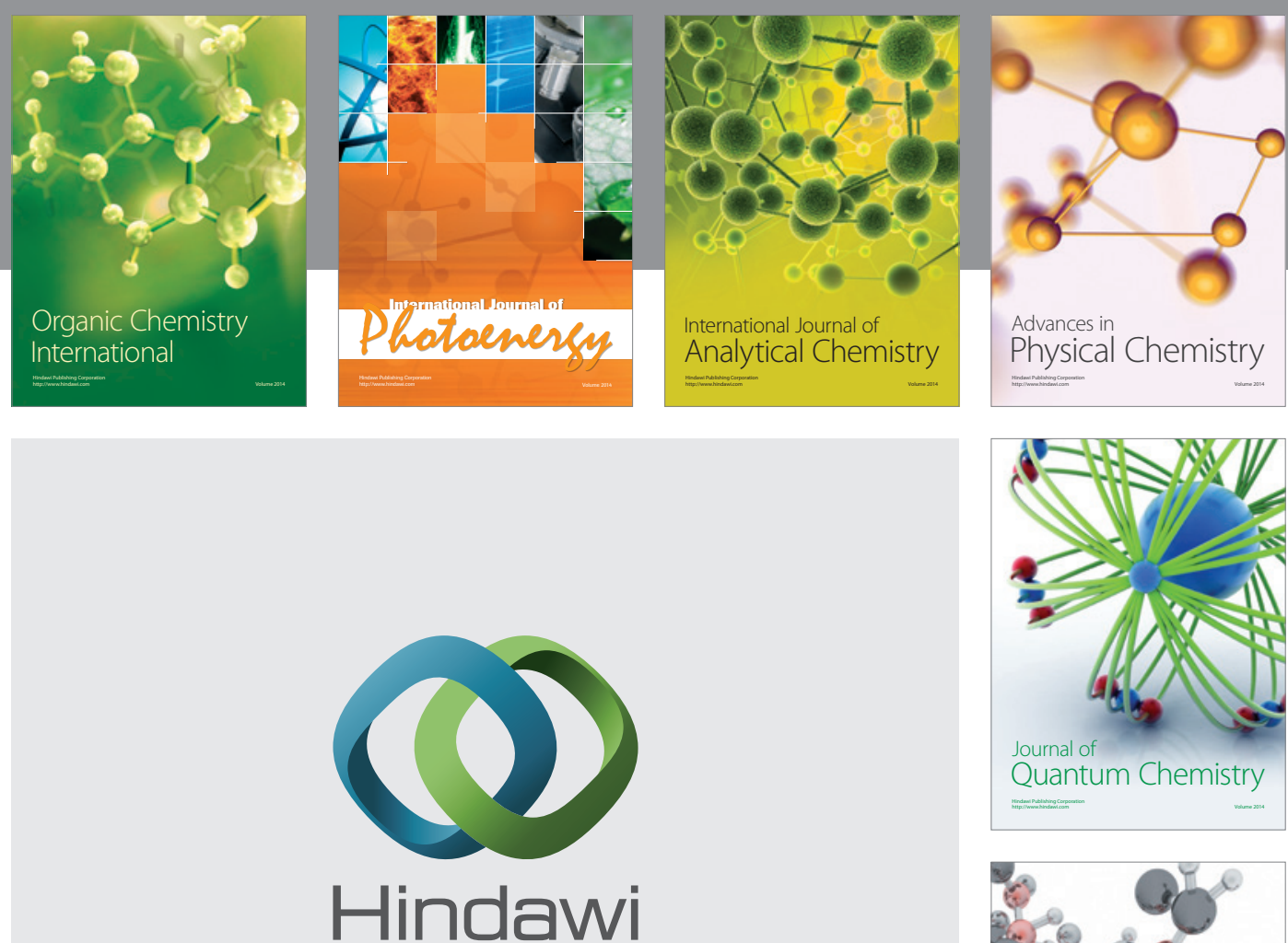

Submit your manuscripts at

http://www.hindawi.com

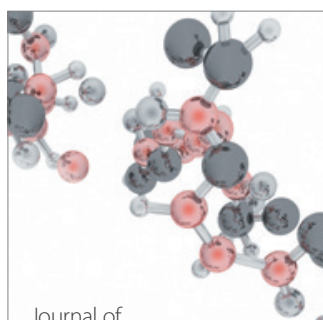

Analytical Methods

in Chemistry

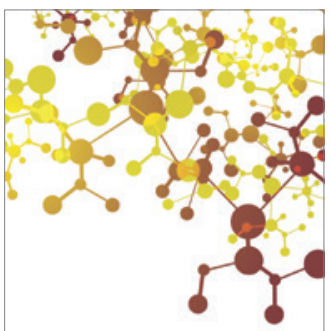

Journal of

Applied Chemistry

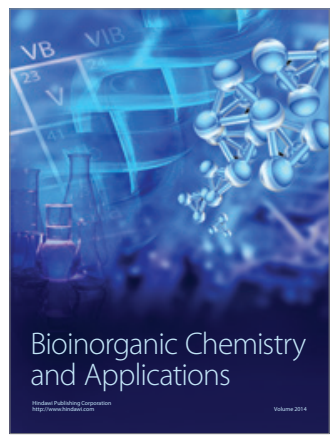

Inorganic Chemistry
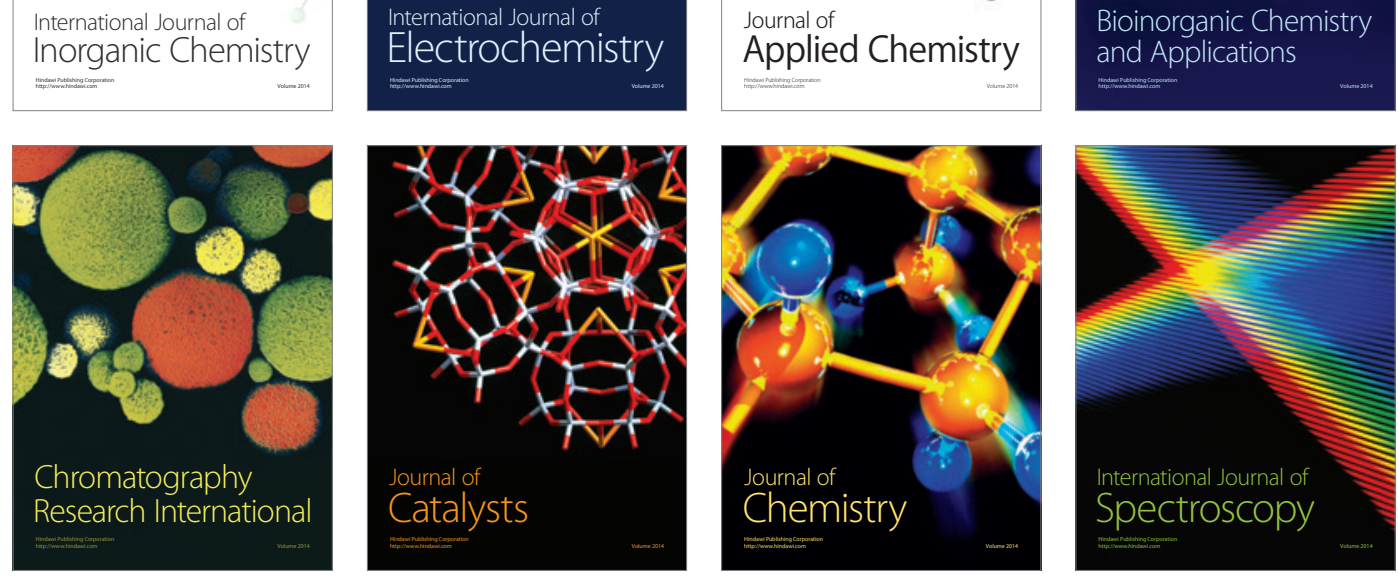